\title{
The Practice and Process of Delivering Integration through Strategic Planning
}

\section{Paula Jarzabkowski and Julia Balogun}

\author{
Aston University; Lancaster University
}

\begin{abstract}
This paper explains how strategic planning is able to deliver strategic integration within organizations. While communication and participation within planning processes are perceived to have an integrative effect, we argue that these effects are unlikely to arise simply from bringing people together. Rather, we suggest that, given the varying interests of actors in different business units, integration will only arise from active negotiations and compromises between these actors. The paper is based upon a case of strategic planning in a multinational that was attempting to develop greater strategic integration across Europe. Drawing upon an activity theory framework, we examine how a common strategy emerges over time through modifications to the planning process and to different actors' roles within it. The findings are used to develop a process model that shows how different business unit characteristics of planning experience and relative power shape different experiences of communication and participation activities and different processes for achieving integration. The paper concludes with a discussion of how this process model contributes to the literature on strategic planning, political processes of strategy-making, and strategy-as-practice.
\end{abstract}

\section{INTRODUCTION}

While some authors have described strategic planning as an annual ritual that delivers little in the way of strategic thinking or genuine change (Mintzberg, 1994), others find that strategic planning remains a widely used organizational practice (Rigby, 2003; Whittington and Cailluet, 2008). Furthermore, organizations are placing increased emphasis on planning as a means of enabling communication, participation, and integration around common goals (Andersen, 2004; Grant, 2003; Ketokivi and Castañer, 2004). Yet empirical evidence for these espoused integration benefits remains mixed (Wooldridge et al., 2008), with many issues raised about the political nature of planning processes and the way that different interests are accommodated. Given that strategy making is inherently political (Guth and Macmillan, 1986; Narayanan and Fahey, 1982), the process by which strategic planning delivers strategic integration between actors in business divisions with different interests remains unclear. This paper thus sets out to Address for reprints: Paula Jarzabkowski, Aston Business School, Aston University, Aston Triangle, Birmingham B4 7ET, UK (P.A.Jarzabkowski@aston.ac.uk). 
investigate those activities that enable participation and communication between actors with different interests, in order to generate the expected benefits of increased commitment to common strategic goals.

Our starting point is that communication and participation are unlikely to result just from 'bringing people together'. Different interests and different experiences of communicative and participative activities by actors occupying different organizational roles are likely to impede the process, leading to only partial integration, or 'lip service' to supposedly shared goals. We therefore need to explore how issues of power, interests, and perceptions of integration arise and are resolved through the negotiations and compromises that occur as actors interact over the plan. An activity theory framework is adopted in order to study these negotiations and compromises from the perspective of multiple participants. We argue that activity theory is particularly well suited to the exploration of how strategic planning delivers communication, participation, and integration because it encourages us to consider the reciprocal processes through which different actors' perspectives and the planning mechanism itself are modified over time in order to enable common activity to emerge (Jarzabkowski, 2005). This view of strategic planning is consistent with the strategy as practice perspective which argues for a focus on strategy making as it occurs through the actions, interactions, and negotiations of multiple actors (Jarzabkowski et al., 2007; Johnson et al., 2003, 2007; Whittington, 2006).

Empirically we draw on a longitudinal, real-time case study of a multinational attempting to deliver greater strategic integration across Europe through the implementation of a new strategic planning system. Multinationals offer a relevant site for the exploration of how integration is or is not achieved in practice across diverse business units, particularly at times of change from a local to a more global approach, as this will require negotiation between previously differentiated and autonomous units (Ghoshal and Bartlett, 1998). Our findings are used to develop a process model that shows how differences between business units, such as planning experience and relative power, create different experiences of inclusion or exclusion and dominant or subordinate roles (Westley, 1990) in strategy making and therefore different responses to communication and participation activities within the planning process. More powerful units experience the process as dominant and exclusive and therefore resist and seek to modify the planning process to reduce its subordinating effects whereas less powerful units actually feel more included and accept their subordinate role. The key contribution of this model is that it accounts for how strategic integration, when it is achieved, emerges out of strategic planning processes through an evolving and reciprocal relationship between the subject positions of different participants and their negotiated modifications to the planning process. This model shows that planning processes should not be reified in the way they often are as imposed actions that actors resist or comply with, but rather how different participants (and their subject positions), strategic plans, and strategic outcomes both shape and are shaped by each other through activities of resistance and compliance. This process model enables us to extend current literature on the political nature of strategic planning and strategy making in general by demonstrating the nuanced and varying nature of communication and participation activities.

This paper starts with a review of the literature on strategic planning, strategy making, and political activity, using this to build the case for the use of an activity theory 
framework. It then describes the empirical setting and methods, before presenting the findings. These findings are used to develop a process model which captures the different paths through which participation and communication activities can enable strategic integration between diverse business units within strategic planning mechanisms. Finally the paper considers the contributions of the findings and the implications for practice.

\section{THEORETIGAL BAGKGROUND}

Various claims have been made about the efficacy of strategic planning. While planning was a staple in earlier strategy studies (e.g. Ackoff, 1970; Lorange, 1975), it has been subjected to considerable critique. For example, Mintzberg (1994) claimed that strategic planning had failed wherever it had been implemented, whereas Miller and Cardinal (1994) found that strategic planning did add value by focusing on the link between strategic planning and firm performance. Such critique is reflected in a steady decrease in publications on strategic planning since 1994 (Whittington and Cailluet, 2008). However, an annual survey by Bain and Company indicates that strategic planning remains one of the most popular techniques used in leading companies worldwide (Rigby, 2003). Recent research also suggests that the communication and coordination function of strategic planning is of key importance to firms. For example, Grant (2003) shows that oil majors value the communicative functions of strategic planning, while Ketokivi and Castañer's (2004) survey highlights strategic planning as a key integrative device enabling diverse organizational divisions to embrace common organizational goals. Others argue that it is precisely this communicative property that makes strategic planning so valuable to firms in a modern environment, where they are increasingly required to cope with uncertainties and to coordinate goals across multiple functional, product and geographic divisions (Andersen, 2000; Brews and Hunt, 1999; Liedtka, 2000; Wilson, 1994).

Consistent with the emphasis on its integrative potential, we follow Andersen's (2004) definition of strategic planning processes 'as organizational activities that systematically discuss mission and goals, explore the competitive environment, analyse strategic alternatives, and coordinate actions of implementation across the entire organization' (Andersen, 2004, p. 1275). Two features of planning, participation and communication, increase its viability as an integrative mechanism. First, participation in strategic planning (Lines, 2004; Mintzberg, 1994) has informational, affective, and motivational effects on different groups' commitment to a common goal. Second, communication of planning goals (Mintzberg, 1994) reduces goal ambiguity because employees know what the organization is trying to achieve. Building upon these two integrative effects of the planning process, Ketokivi and Castañer (2004) find a complementary association between communication and participation that enhances integration effects when both are used.

These findings on the integrative role of strategic planning raise many questions about the social dynamics involved in integration. While communication and participation may help to achieve organizational integration around common goals (e.g. Andersen, 2004; Ketokivi and Castañer, 2004; Mintzberg, 1994; Vancil and Lorange, 1975; 
Wooldridge and Floyd, 1989), it is not clear how groups with different interests develop shared understanding or at least common pursuit of the same strategic goals. Implicitly, the findings suggest that communication and participation have integrative effects by 'bringing people together'. However, empirical evidence on the integrative effects of strategic planning is mixed (e.g. Wooldridge and Floyd, 1989, 1990). In particular, even when people interact directly in the planning process, some interests are suppressed and others promoted in ways that affect commitment to strategic goals (e.g. Hardy et al., 2000; Jarzabkowski, 2008; Narayanan and Fahey, 1982; Westley, 1990). Thus, findings on the integrative effects of strategic planning need to be elaborated through fine-grained studies of the compromises, interactions, and negotiations that take place over the planning process. These social and political interactions over strategy making are at the heart of the strategy-as-practice perspective, which calls for studies that illuminate the micro-activities involved in the social accomplishment of strategy (Jarzabkowski, 2005; Jarzabkowski et al., 2007; Johnson et al., 2003, 2007; Whittington, 2006). There is, however, little research into how the integrative effects of planning are constructed in practice, through the actions and interactions of multiple actors with different interests. Our paper responds to this gap in the literature. We first examine issues of communication, participation, and politics in strategic planning, then propose an activity theory framework as way of understanding how planning processes can be used to develop integration.

Strategic planning is perceived as important for communicating an organization's strategy internally and externally (Bartkus et al., 2000; Beer and Eisenstat, 2000; Kotter, 1995; Mintzberg, 1994). While most of these authors have assumed that communication occurs after a plan has been formulated, others indicate that communication is important during formation in order that different organizational actors can have input into the plan (e.g. Grant, 2003; Ketokivi and Castañer, 2004; Lines, 2004). However, the communicative purpose of planning, the activities that are involved in communication, and its impact on either organizational members or on the planning process itself are still under-researched. Organizational goals are seldom unitary, as they may originate with one group of actors, top managers (Simon, 1964), but then be significantly modified, or indeed new goals may be motivated, by middle managers (Bower, 1970; Burgelman, 1983; Burgelman and Grove, 1996; Floyd and Lane, 2000). In particular, goals are not stable but rather emerge and are modified through the communication process (Hardy et al., 2000). Hence, it is important to study how goals that are communicated through strategic planning are modified and adapted over the course of the planning process, in order to become goals to which all members can subscribe.

Many studies of strategic planning as an integrative device largely view participation as a socialization mechanism that generates shared meanings (Lines, 2004). However, nuanced studies of participation indicate that identification with common goals varies according to the nature of the participation activities and the social positions of different actors (e.g. Korsgaard et al., 1995; Mantere and Vaara, 2008; Sagie and Koslowsky, 2000; Schaffer and Willauer, 2003). For example, the extent of socialization may vary according to the gap between participants' desired and perceived levels of participation (Driscoll, 1978). The association between participation and common goals is complex, as individuals participate in multiple communities, through which they construct a range of 
interests and identities that may not align with organizational goals (Handley et al., 2006). Thus, subjects may experience participation in different ways, from a threat to their own autonomy, to a political or social opportunity, according to the different roles that they construct for themselves within the organization (Musson and Duberley, 2007). These roles may also shape the way that actors participate. For example, Mantere and Vaara (2008) find that actors at different organizational levels, such as top versus middle managers, may construct different ways of participating in strategy processes. These varying nuances in participation activities, the way that they are experienced by different actors, and the way that different actors attempt to engage in them, indicate that the way in which participation enhances the integrative effects of strategic planning is complex and bears further investigation.

The wider literature on strategy and decision processes in particular provides insights into the political issues that might obscure some of the participation and communication effects on strategic planning. Strategy making is an inherently political process (Chakravarthy and White, 2002; Eisenhardt and Bourgeois, 1988; Narayanan and Fahey, 1982), which is sometimes overlooked in the literature specifically on planning. Strategy making involves self-interested parties with different perceptions of what constitutes an appropriate organizational goal (Narayanan and Fahey, 1982). The negotiation of self-interest is particularly likely to play out in the interactions between different organizational roles, in which top managers attempt to establish strategy and middle managers either seek to influence the strategy according to their own interests, or to resist its implementation where it does not meet these interests (Balogun and Johnson, 2004; Floyd and Wooldridge, 1997; Guth and Macmillan, 1986; Narayanan and Fahey, 1982). Lower level managers gain influence through various forms of coalition formation that enable them to have greater influence on the strategy process, despite their apparent lack of hierarchical power (e.g. Balogun et al., 2005; Narayanan and Fahey, 1982; Westley, 1990). There is a focus in these studies on resistance to and influence upon the strategy process arising from actors in different hierarchical positions in the organization (e.g. Floyd and Lane, 2000; Mantere, 2008; Mantere and Vaara, 2008). Indeed, Quinn (1980) proposed that in order to overcome political and emotional resistances, strategy-making should proceed incrementally, learning from and adjusting the strategy according to the feedback received over time. Hence planning mechanisms do not necessarily enable strategic decisions to be implemented but rather serve as mechanisms through which managers at different levels are able to influence strategic action (e.g. Bower, 1970; Burgelman, 1983; Chakravarthy and Doz, 1992; Chakravarthy and White, 2002; Floyd and Lane, 2000; Jarzabkowski, 2008). In particular, iterations over a planning process enable different actors to negotiate their own interests (Chakravarthy and Lorange, 1991; Dutton and Duncan, 1987; Johnson, 1988; Quinn, 1980).

Different interests, particularly between middle managers and top managers, have received growing attention. These differences are an inevitable part of the strategic decision process that can either give rise to conflict and obscure strategy implementation (e.g. Guth and Macmillan, 1986), or alternatively be productive, giving impetus to strategic renewal (Bower, 1970; Burgelman, 1983; Burgelman and Grove, 1996; Floyd and Lane, 2000; Rouleau, 2005). Middle managers are important not only for implementing strategies but also for facilitating strategic change and giving impetus to or 
championing new strategies to top managers. Thus, the way the inevitable conflict is managed is important. For example, increasing middle manager integration into the strategy process has been associated with increased firm performance (Floyd and Wooldridge, 1997). That is, reducing conflict may increase consensus, smooth implementation, and so enhance firm performance (Wooldridge and Floyd, 1989). However, performance enhancement also occurs from participation in strategy-making activities, even when consensus between different organizational levels is not an outcome (Wooldridge and Floyd, 1990). There is thus something powerful about participation in the strategic planning process that has positive effects, even where consensus is not an outcome. The different interests of those occupying different roles within the strategy process may be managed through reciprocal interaction, vertically and laterally (Balogun and Johnson, 2005; Mantere, 2008), adaptive control systems (Floyd and Lane, 2000; Marginson, 2002), and flatter organizational structures that enable increased communication (Wooldridge et al., 2008). However, there has been little fine-grained empirical research into the dynamics through which different level actors are involved in strategy making (Wooldridge et al., 2008, p. 1209) or how intra-organizational relationships are realized within strategy making (p. 1213).

The way that political processes play out will also be influenced by the way in which the organization values input from different actors in the strategy process (Dutton and Duncan, 1987; Westley, 1990). Actors assume or are allocated different political roles in the strategy process (Narayanan and Fahey, 1982). However, we know little about how such roles are assumed or allocated, or their implications for the outcomes of the planning process in terms of consensus or shared goals. It is not simply the fact of inclusion in a strategic conversation that enables managers at different levels to feel committed to a strategic goal (Westley, 1990). Even when they are included in a strategic conversation, lower level managers may be allocated a subordinate role, in which the scope of views that they may express and the emotions that they may feel about the strategy are demarcated by senior managers. Such findings indicate that we need to pay greater attention to how different level actors perceive their inclusion and ability to influence those strategic planning activities in which they participate if we are to account for their varying experiences of integration.

Taken together, the above literature indicates that strategic planning is important within organizations because it has an integrative effect. Furthermore, this integration arises from the communicative and participative properties of strategic planning. However, communication, participation, and the subsequent integration that is to arise from planning is likely to be fraught with difficulties arising from different interests and experiences of communication and participation activities by actors occupying different organizational roles. We therefore need to develop more nuanced understandings of strategic planning as it occurs in practice, in order to understand how issues of power, interests and perceptions of integration arise and are resolved through the negotiations and compromises that occur as actors interact over the plan. In particular, we need to understand how these interactions enable the planning process and the goals and interests of different actors to be modified to the extent that common organizational goals may be pursued. In doing so, we respond to calls for future research 'to examine these dynamics and to extend the work of Ketokivi and Castañer (2004) in describing 
conditions that help to align individual and subunit interests with those of the larger organization' (Wooldridge et al., 2008, p. 1216).

\section{Activity Theory Lens}

We now propose an activity theory framework for examining the strategic planning process over time. Activity theory is a useful conceptual apparatus because it suggests that planning will be experienced differently by different actors according to their different interests and that the planning process itself plays an important role in these experiences. While the planning process is put in place to mediate between different interests, actors also seek to modify the planning process according to their own interests, using it to dominate other actors or to advance their own interests. Activity theory is a useful framework for analysing these reciprocal strategy processes because it is fundamentally concerned with understanding dynamic processes over time; 'Let us take the metaphor that strategy process is like a river. . . This metaphor helps to understand why dynamic aspects of a larger active process cannot be fully explored with static samples from that process. Process, contexts and outcomes all change with time' (Chakravarthy and White, 2002, pp. 200-1). While process, context and outcomes continuously evolve in interaction with each other, we have few strategy studies that explicitly adopt an ontological framework that allows them to explore this reciprocal process. However, this reciprocity is at the heart of practice-based studies (see, e.g. Jarzabkowski, 2008; Orlikowski, 1996, 2000). By adopting an activity framework, we take a practice-based ontology, as espoused by multiple authors (Jarzabkowski, 2004; Johnson et al., 2003, 2007; Whittington, 2006), in order to analyse strategy as a continuously unfolding stream of activity that is constructed through the interactions and negotiations between different actors.

Activity theory (Leontiev, 1978; Vygotsky, 1978) is increasingly being drawn upon to look at problems of coordination and shared activity in organizations (e.g. Adler, 2005; Blackler, 1993, 1995; Blackler and McDonald, 2000; Blackler et al., 2000; Foot 2000; Jarzabkowski, 2003, 2005; Miettinen and Virkkunen, 2005; Spender, 1995). In these studies, the organization is conceptualized as an activity system, accomplishing common activity through the interactions within the system. Three concepts in activity theory are useful for looking at our problem of strategic planning as an integrative mechanism: goal-directed activity; subject; and mediation. Activity theory focuses upon practical activity as the goal-directed interactions through which actors engage with their contexts over time. Practical activity provides a focus for interactions; different actors interact in order to $d o$ something. These actors each have their own concept of the purpose of the activity, based on their localized understandings about 'the way we do things here' (Spender, 1995), that will need to be modified in order to establish common activity for the system as a whole. If an organization is to achieve common strategic actions, these will comprise partly corporate-communicated intentions about what the organization should do and partly emergent features of localized divisions' own activities and interests (Blackler et al., 2000, p. 284). The focus or 'goaldirectedness' of activity is thus evolving, emerging out of the interactions and contests between actors, and this is a key feature of activity theory analysis; examining how a 
collective output is accomplished through interactions and contests between actors, which modify both the goal and how the actors engage in actions directed at the goal (Engestrom et al., 1999; Foot 2000).

In activity theory, actors are conceptualized as subjects who interact purposefully with their contexts; 'People act as subjects in the world, constructing and instantiating their intentions and desires' (Kaptelinin and Nardi, 2006, p. 10). It is through this subject's intentions and actions that activity may be understood. Such activity is always collective, in so much as, even in acting alone, an actor relates to the collective and draws upon the tools and symbols of that collective. While individuals act by drawing upon and contributing to collective tools and symbols, they are not simply pawns of the collective. Rather, they have motives and desires that they impute to their own actions within wider collective activity. This concept of subjects as purposeful actors is important for studying the problem of strategic planning as an integrative mechanism. It indicates a focus on the purposes that different actors attribute to their own actions within the planning process and its resultant outcomes. In particular, this framing invites us to compare different subjects and understand interactions from different subject positions. We thus have a richer view of the communication and participation activities through which strategic planning generates integration. From an activity theory perspective, we cannot look at strategic planning as a set of common organizational goals that must be communicated to other actors, in order that they might adopt those goals, but rather as a study of how different actors interact with the goals that are presented and what modifications are necessary to accomplish those goals as common activity.

Mediation is the third activity theory concept drawn upon in this paper; 'Activity theory casts the relationship between people and tools as one of mediation; tools mediate between people and the world' (Kaptelinin and Nardi, 2006, p. 10). Mediating tools or mechanisms can take social, physical and cognitive forms, such as operating procedures, heuristics, scripts, routines, and languages (Omicini and Ossowski, 2004). Mediation suggests that, despite their potentially different perspectives and interests, actors are able to integrate their actions in the pursuit of shared activity (Engestrom, 1993; Kozulin, 1990). However, activity theory does not conceptualize mediation mechanisms as primarily the instruments of any particular constituent, such as senior managers (Jarzabkowski, 2009). Rather, the same mechanisms may be appropriated by different constituents in order to mediate between their varied purposes and interests (Rabardel and Beguin, 2005). From this perspective, strategic planning is a mediating mechanism that cannot simply be imposed but must be brought into being by the actors who participate in it, during which process it will be modified. This is because strategic planning has a 'general' or cross-contextual character when it is introduced, which will come into tension with the local situated actions of different subjects (Miettinen and Virkkunen, 2005, p. 444). Thus, different subjects continuously interact with the planning mechanism, modifying it to suit their own interests, even as these interests are modified by the planning process. Such modifications involve ongoing and unfolding power dynamics (Blackler and McDonald, 2000), as new ways of relating and new activities emerge around reactions to and modifications of the planning process. Mediation is therefore a valuable concept for examining the integrative role of planning 
processes in organizations (Blackler, 1993, 1995; Blackler et al., 2000; Jarzabkowski, 2003, 2005; Miettinen and Virkkunen, 2005). It goes beyond simply explaining how common strategic actions are integrated through planning, possibly with some resistance, to examining how common strategic actions, different actors' interests in those actions, and the planning processes that mediate between them evolve together.

However, we have few studies that examine these reciprocally evolving processes within strategic planning (Chakravarthy and White, 2002). Rather, planning processes are reified as 'things' which actors resist or acquiesce, with little understanding of how the process is itself accomplished through resistance and acquiescence, and how that process also shapes the participants and the activity in which they engage. An activity theory perspective is, therefore, adopted in this paper in order to explore the reciprocal relationship between the planning process, actors' subject positions, and the emergence of common strategic activity. The paper seeks to explain the process by which strategic integration is ultimately delivered, identifying the specific types of modifications that need to take place in the planning process, the actors involved in that process, and the way that a common strategy emerges.

\section{RESEARGH DESIGN AND METHOD}

As typical in longitudinal case-based research, we used theoretical sampling to select a case that reflected the phenomena under investigation (Eisenhardt, 1989; Pettigrew, 1990). Access was granted to the European Division of Brandco, a large producer of branded consumer goods, that reflected the traditional multinational with a country centric way of working (Ghoshal and Bartlett, 1998). We were able to track longitudinally the evolution of a new annual strategic planning process established in 2004 to achieve greater strategic integration across Europe. Multinational firms that are using strategic planning in an attempt to deliver globally integrated strategies are an appropriate site in which to examine the integrative effects of strategic planning (e.g. Ghoshal and Bartlett, 1998; Ketokivi and Castañer, 2004). We chose to focus on one in-depth qualitative case study to enable us to capture a multi-level perspective and be closer to the actions and interpretations of the participants involved consistent with a strategy as practice perspective (Balogun et al., 2003; Johnson et al., 2007). Whilst single site case studies have their limitations, topical contexts, such as here building strategic integration across Europe, give findings broader relevance (Balogun and Johnson, 2004).

The new planning process was facilitated by the creation of new European Marketing Teams (EMTs). Consistent with our research problem, the new EMTs were intended to create integration while allowing for locally tailored delivery. Specifically, the EMTs were to develop new pan-European strategies and campaigns by working collaboratively with the country-based brand teams, who were then to implement these strategies locally. We focus on the EMT and associated planning processes for Brand X. The Brand X EMT was located in the UK and sponsored by the UK Country President but it was to work in a pan-European fashion. The new strategy was to be implemented through a new annual planning process, which comprised a series of activities occurring at the EMT-level, the country-based brand teams level, and also at the Divisional Management Team level and the country-based senior management teams, providing a 
Table I. Timeline for strategic planning process

\begin{tabular}{|c|c|}
\hline Month & Planning activities/key actors \\
\hline Jan-Mar & - European Strategy Development/EMT \\
\hline Mar & $\begin{array}{l}\text { - Sign off (by Divisional Management Team) and issue of European Strategy to local market } \\
\text { teams/EMT }\end{array}$ \\
\hline Apr-May & $\begin{array}{l}\text { - Key Issue Development/Local Market Teams } \\
\text { - European Campaign Development/EMT }\end{array}$ \\
\hline June & - Key Issue review meeting/EMT and Local Market Teams \\
\hline July & $\begin{array}{l}\text { - Sign off (by Divisional Management Team) and issue of Campaign to local market } \\
\text { teams/EMT }\end{array}$ \\
\hline Jul-Sept & $\begin{array}{l}\text { - Market Plan Development/Local Market Teams } \\
\text { - Campaign Translation and Implementation/Local Market Teams }\end{array}$ \\
\hline Sept & $\begin{array}{l}\text { - Sign off of market plans by country presidents/Local Market Teams } \\
\text { - Continued campaign Translation and Implementation/Local Market Teams }\end{array}$ \\
\hline Sept & $\begin{array}{l}\text { - Market Plan Review Meeting/Local Market Teams and EMT } \\
\text { - Continued campaign Translation and Implementation/Local Market Teams }\end{array}$ \\
\hline Sept-Nov & $\begin{array}{l}\text { - Ongoing negotiations with large markets/EMT } \\
\text { - Ongoing negotiations with EMT/Large Local Market Teams }\end{array}$ \\
\hline
\end{tabular}

series of natural data collection points (see Table I). Implementing the process was challenging, as different geographic regions had different levels of knowledge about the product, the market and, particularly, the planning process, while different hierarchical levels had diverse interests that they wished to realize through the new planning process.

We took a longitudinal, qualitative, case-based approach (Eisenhardt, 1989; Pettigrew, 1990). In order to track over time developing reciprocal relationships between the planning process, the different actors' subject positions, and the emergence of common strategic activity, we tracked the planning process from the perspective of the key actors: the Brand X EMT and the European Brand X teams, including the European Brand Network (EBN) members of the key geographic regions. As the second author had long research engagement with the company, we quickly were able to identify and access the key players, as well as having considerable contextual understanding of the case study. Specifically, we collected data from most of the main regions into which Brandco divided its European market: the UK, Germany, France, Spain, and Nordic and Central Europe. Additionally, as the EMT was based in the UK and sponsored by the UK Country President, we interviewed UK senior managers involved in the change. Data were collected primarily through 30 interviews conducted from March 2004 to January 2005, with dates coinciding to key events in Table I. Each interview lasted about an hour and all were audio-recorded and transcribed. We also collected copies of the pertinent strategic planning documents and presentations, in order to analyse what the planning process entailed and how different groups engaged in the planning activities. To further triangulate, we reported our findings to the Head of the EMT, the EMT Marketing Director, and the UK Country President (also sponsor of the Brand X EMT) at a one and a half hour meeting in 2005. Detailed notes including verbatim quotes were taken during this meeting and subsequently typed up. 
Our interview questions focused on how the new planning process was perceived by the EMT and Brand X teams in the different geographic regions at different points in the strategic planning process; what changes in strategic activity they were experiencing; and how they perceived their own position within the planning process and within common European strategic activity. The data collection was split between the authors, enabling each author to be immersed in the activities of specific hierarchical and geographic communities, whilst cross-checking impressions and tentative findings after each set of interviews in order to inform subsequent rounds of interviews. This research design enabled us to access the subject positions of the key hierarchically- and geographicallybased participants responsible for managing the new integration process, conducting repeat interviews at key points in the process, so that we could trace how subject positions changed over time, in interaction with changes in the planning process and changes in perceptions about common strategic activity. In order to ensure trustworthiness in our qualitative data, we followed many of the criteria laid down by Lincoln and Guba (1985). The second author had prolonged engagement with the research site, not only during this research project, but also through previous research projects. Multiple sources of data collection were used. The final report and meeting provided research participant feedback. Finally, the research was written up through a thick description of the findings to enable their transfer to other settings.

\section{Data Analysis}

Analysis progressed over five stages. We adopted an inductive approach to the data (Miles and Hubermann, 1994) in order to develop emergent themes, which we followed by iterative references to the theoretical framework in order to interpret our findings and develop labels for particular themes that arose (see Eisenhardt, 1989; Suddaby, 2006). First, each author constructed rich narratives of the strategic planning activities of those groups she had tracked (Langley, 1999). These narratives provided thick descriptions of each group's perceptions of their own and others' activities in the new strategic planning process and how they acted to shape the planning process according to their own perceived subject position within the common European strategy. We then read and discussed each other's stories, with each author acting as an 'outsider' in questioning the findings and themes of the other's story (Evered and Louis, 1981).

In the second phase, based on our discussion of the stories, we identified that different actors could be grouped according to the way that their different subject positions evolved within the planning process. Specifically, drawing on political frameworks (see Narayanan and Fahey, 1982), we looked at the positions that particular groups either assumed in the planning process, meaning the way they self-identified in that position, or were allocated, meaning the way that they were identified by others. Our three groups were:

- The European Marketing Team (EMT), which assumed a subject position as strategy formulators and allocated others a subject position as strategy implementers. 
- Large European Markets, which initially assumed a subject position as strategy formulators, resisted the allocation of a position as strategy implementers, and eventually assumed a position as strategy translators.

- Small European Markets, which were initially allocated a position as strategy implementers and came to assume that as an appropriate position.

Third, drawing upon the concept of mediation in our activity theory framework we analysed these evolving subject positions in relation to the planning mechanism, examining how different subjects drew upon the mechanism in order to justify either the positions that they assumed or how they sought to modify it, in order to better meet the positions that they wished to assume. For example, we found that the EMT emphasized standardization of the planning process in order to reinforce their assumed position as strategy formulators, while Large Markets tried to modify the planning process in order to assert their own position as formulators, or to discredit it in order to resist the allocated position of strategy implementers. We traced the meanings that different groups attributed to the planning process in order to justify their own actions and how the groups negotiated and modified the process over time until it could deliver a common understanding of integrated European strategy.

Fourth, we tied these analyses of subject positions and planning process modifications together by comparing and contrasting the different groups' experiences of integration over time, particularly in terms of how they referred to communication and participation activities. In this analysis, the different experiences of communication and participation that we found could be usefully interpreted with reference to Westley's (1990) concepts of inclusion/exclusion and domination/subordination/codetermination within strategic conversations. That is, we recognized that the way that the way that groups were attempting to modify the planning mechanism and their own subject positions were associated with their different experiences of inclusion or exclusion and domination, subordination, or codetermination in particular communication and participation activities within the planning process.

Fifth, we compared the different subject positions, experiences of integration and attempts to modify the planning process, in order to derive some understanding of the different way that the process unfolded over time for Large Markets and Small Markets, and the different way that the EMT responded to these two groups. From this analysis, we recognized that two main characteristics of the different groups were important in the different processes: the extent of a particular market's experience of planning and the extent of intra-organizational power of a particular market, in terms of its market size and revenue with Brand $\mathrm{X}$. This final analytic stage enabled us to develop a process model explanation of our findings, which is presented in the discussion section of the paper and constitutes our main contribution.

We now present our findings over three phases, showing how each group's subject position evolved in association with that group's experiences of integration as inclusion or exclusion and domination, subordination, or codetermination and that group's attempts to modify the planning process. 


\section{FINDINGS}

\section{Phase 1}

Phase 1 covers the period from the April strategic issue development through to the June key issue review meeting, each of which were parts of the new planning process (see Table I). April provided an opportunity to communicate the new strategy, while in June different geographic markets were able to participate in the planning process by sharing their key issues based on the EMT's new strategy at a review meeting. At the same time, the EMT had set up the European Brand Network (EBN), comprising regular meetings between the EMT and members of all the main local markets and regions, in order to enable ongoing communication of and participation in strategy across local markets. From the outset, it was apparent that strategic planning had been introduced into a context in which actors had different experiences of strategic planning, different levels of Brand X penetration within their markets, and different time horizons for developing a Brand X portfolio within their markets. There were thus different subject positions in relation to what strategic planning constituted and where strategy should be formulated for Brand X.

EMT assume a position as strategy formulators. At the outset, the EMT were keen to embrace communication and participation as a way to ensure that strategic planning could deliver a common European strategy:

... I see us as the coordinators, facilitators, and the people who have to make the call at the end of the day, but actually there are extended members of the EMT within the market. We have single, senior marketing representatives from each of the major countries and each of the major regions sitting on, as we call it, the EBN. We very closely work with them in strategy development, information gathering, campaign development and roll out.

At the same time, however, they saw strategic planning as a useful standardization tool that could cause local markets to behave in similar ways:

I want to be able to sit there looking at Italy, Germany, Spain, the Northern region, the Southern region, and actually be able to benchmark and see the consistencies and inconsistencies across Europe, so if someone comes in and says OK, this is what the market analysis has said they are using the same parameters to analyse their market as someone in Italy or Spain. Otherwise it is incredibly difficult for me to sit there and say that's a good plan, that's not a good plan, here's the challenge, and here's the support.

This view of planning, which involved the development of a common set of planning templates to be used by all local markets, indicated two points. First, from the EMT perspective, integration was possible because local markets were perceived as largely undifferentiated. If markets had inconsistencies, planning provided comparators to benchmark and standardize outputs. Planning was thus not only about communicating 
a common strategy but also about ensuring that the EMT could evaluate common output across markets, leading to the second point. As local markets were undifferentiated, the strategizing role of actors in local markets was negated, emphasizing a particular subject position for the EMT as strategy formulators, who adjudicated on local strategy. Despite their initial intentions to be strategy coordinators and facilitators, with strong participation from local markets, as the standardizing aspects of planning took hold, the EMT assumed the position of strategy formulators. They thus assumed a dominant role in integration activities:

We are there to set the European strategy which includes brand positioning and includes the key messages and includes the campaign.

Small markets are allocated a position as strategy implementers. Small markets, with little experience in strategic planning, found the new process, with its templates and rigorous planning format, quite challenging:

In Finland we never kind of split the planning process in two so kind of firstly the issues and kind of OK on those, and then go onto the next phase which is how we are going to solve these things ... So people are not so used to ... They are used to filling in templates but they are not so used to kind of understand why they should do. (Nth EU)

At the same time, smaller markets played a small part in the Brand $\mathrm{X}$ market penetration and revenues:

And very different market situations as well, so in some markets the product was launched two years ago, and is quite successful. In other markets the product is still not available. (Central EU)

If you represent one country and come back home and basically these guys normally also work with Brand X products ... it's their kind of their main work. While representing a country or area ... I didn't even know what Brand X was when I started to represent Northern Europe. (Nth EU)

Thus, small markets' experiences of communication and participation activities were largely of a subordinate nature as they tried to learn about both Brand X and about more formalized ways of planning.

While the new experiences were challenging, the small markets also began to perceive that this new process could support them in implementing a Brand X strategy:

It doesn't take away any work load, but it actually adds things, analysis etc, you know, materials that you were not able to produce before. (Nth EU)

In this way when I work locally I can count on the support of those programmes that have been at the European level and I can profit and capitalize on those a lot. (SP) 
Small markets thus embraced opportunities to participate with other markets and the EMT.

Large markets assume a position as strategy formulators in their own markets. The large markets were already experienced in strategic planning. They had considerable market share in Brand X and were important revenue streams for Brandco. When they heard about the EMT, the new planning templates, the common strategy, and the common campaign for Brand X, they were relatively unconcerned, seeing this as having little influence on their actions:

It is good to have a common way of us presenting the figures, that's OK, but for the action plans, actions are very different from one country to another one. (FR)

They expected that the planning process was largely to help develop the smaller, inexperienced markets:

I think if you are talking to some other countries my observations are that somebody can go through that planning process with much more, like a new thing for them and make them consider elements of the situation analysis that they have never considered before. (UK).

Due to their experience in formulating strategy, they expected to have a lot of input into the common European strategy:

So I see it as two-way . . . they will have to market ... there will be a lot of communication between the markets and the EMT to develop strategy, and then actually implement it. (UK)

As these large markets participated in strategic planning sessions with the EMT and other countries, their perceptions about the importance of Brand $\mathrm{X}$ and its different positioning in their markets were reinforced:

Needs are different: we were so different in our key issues, and the market is ... was at this time totally different, the position of Germany and France regarding the product was totally different... we were not at the same time in the same situation. (FR)

... the UK is a very different market. ... we are in a very different place. (UK)

In our case, we had a slightly different understanding of what the key issues are for Germany. (Germany)

They were thus convinced that they would participate in developing common elements of strategy, whilst maintaining their own distinctiveness as important, knowledgeable markets with good experience of planning for their own markets. 
As the planning process evolved and the EMT began to take a stronger view of planning as a standardization tool for adjudicating on what they saw as largely undifferentiated markets, so these larger markets developed a negative view of the communication and participation they were experiencing:

A classic one is this week when it could have been a slide show that they could have sent to everyone, because they didn't get that debate. And my brand planner said, you know, everyone was quiet listening to the presentation. That to me isn't an effective EBN and how we should be working. I think we should really be challenging understanding ... the debate is where we move on and develop strategy. To me it is not coming from ... . if they just do a load of PowerPoint presentations to everybody and they take it . . . nobody owns that then. It's the EMT Marketing Director and his team that own it, we don't in EBN. (UK)

Hence, as they moved towards the June review meeting, large markets felt that, even so that they were being physically included in communication activities, they were being excluded from participating in formulating the strategy. They thus experienced their dynamic with the EMT as one of domination and subordination that was inappropriate to their position as strategy formulators.

\section{Phase 2}

In Phase 2, which began with the June key issue review, and progressed to the development of Brand $\mathrm{X}$ market and campaign plans, the patterns of differentiation that emerged in the previous phase were accentuated, provoking resistance. At the June meetings, many markets, small and large were exposed to the standardization of the planning process, as they were pulled into line for not developing appropriate 'key issues', based on the EMT's templates and definitions:

And now in June, last week, we had meetings with all the most important countries from the regions. And they presented those key issues to us, we had the discussion ... And then, if you agree with them the strategic direction and the key issues, then they go back and they write plans to address to those key issues and plans. (EMT)

EMT assume a stronger position as strategy formulators. The EMT ambitions for the June meetings indicated some contradictions in their perceptions of communication and participation. They felt the June reviews should generate key issues for each country consistent with the EMT strategy for Brand X, because they had used the EBN to communicate the strategy and expectations, indicating that they were already quite entrenched in their own subject position as strategy formulators, with planning as a mechanism for communicating that strategy:

Actually we have taken them through each step of the start up document, so that actually there's more understanding of what we are asking them to do and why we are asking them to do it. 
At the same time, they clung to views of strategic planning as participative:

I've chosen to do that one [June] by a meeting as well, or several meetings so we get several countries together presenting their plans to us, so it doesn't feel quite as much of us going and saying, right, present a plan, you know we are the superior bods with great brains, because that's not the case at all ... we are trying to add support and actually challenge them to get the most out of every part of the business.

However, at the June meetings, the EMT actually reinforced their positions as strategy formulators, using the standardization of the planning mechanism to dominate other parties:

It all used to be about strategic options ... and the key messages and the campaign, and how are we going to implement, as well as the tactics. All that's going to be gone. They should just be, in these templates, sticking in what we are saying . . . and the key messages should be exactly what the EMT said they are.

Small markets assume a position as strategy implementers. Small markets began to realize that these planning templates, review meetings, EBN meetings, and the subsequent campaign aids being developed were to their advantage. They recognized that their opportunities for participation in formulating European strategy were limited and that they would need to conform to common activity if they wanted to gain traction with Brand X:

Actually in one of the sessions when all the Northern European GMs were there, I just had to stand up and say, guys, you are way out of line here . . you need to understand what you can effect and what you can't effect, and you know you should stop discussing those things where actually you don't have the power to say anything about this ... we are not actually changing the strategy, we are actually coming to really think how can we, in our country, or in our region, or whatever, do the best in terms of implementing things. (Nth EU)

They thus curtailed their expectations of participation in strategy formulation, trading these off for the value of participating in implementation plans with more experienced European countries:

So to me even though it is a much more different country, the tactics on some of the issues, the approach to the issues is quite useful to me because I like to see what happened there so what can we take from that and how did they approach to this. So in that way that interaction is quite good. (SP)

These trade-offs enabled small markets to accept their subordinate role in the planning process and to assume the subject position of implementers of a common European strategy that had been allocated to them by the EMT. They thus began to experience the EBN meetings and interactions with the EMT as participative and were willing to subordinate their local differences: 
And I felt really, really involved. We all know that when you work with different European countries everyone has their own peculiarities, or how do you say, their local things. But all the, everyone had the opportunity to provide with input and try to bring here the Spanish situation or what ever the situation is to be. So in that way I think there was much of a consensus going on in between all the decisions. (SP)

As small markets had gained by accepting the subject position of strategy implementers and the associated standardization in planning, they were amenable to adopting the EMT designed campaign with no amendments other than translation into their own language and amending plans at the September sign-off as requested, which further reinforced their subject position as strategy implementers:

Honestly I must say that the smaller markets would never have a strategy for our brands in the first place without the EMT, so really it's just great that we now have one. (Nth EU)

So coming from a small market like Hungary, and I see the same in other markets in the region, I can see that we never did such a professional market research and strategy and planning procedure like in this case with Brand X. (Central EU)

This strategy implementer position was complementary to and reinforced the EMT position as strategy formulators, reinforcing the dominant-subordinate dynamic in communication and participation activities. Thus small markets became increasingly integrated into a common European strategy through their acceptance of the standardized planning process and their role in it.

Large markets resist the EMT allocated position of strategy implementers. In the large markets, the challenges at the September meeting and over the campaign affected their experiences of the planning process. They realized that they were not able to use their local knowledge to participate in common strategy formulation. They thus began to disparage the planning process as largely irrelevant, rather than as opportunities to participate in strategy-making:

What I am not seeing from the EMT is say, Germany did this, and it was fantastic. What a great idea. We don't see that, sort of, sharing of best practice. What they seem to be doing is generating support for the markets that are needing to come up to a certain level, but actually the other markets that are already there... There isn't enough to sort of push them on. (UK)

They began to assert the importance of their local markets and adherence to their local procedures during the market and campaign development:

We have a German planning process, a German business team, all the key stakeholder functions are in this team and what we actually did, we split up the work and used our core competences from different team members and gathered the plans in a way that 
we all agree on it. ... So I think the direction, where we are going with Brand X . . if there are then some specific things for the adjustment of the strategy to the German market, that is certainly in my understanding, the responsibility of the market. (DE)

In this reaction to what they perceived as an overly standardized planning process, the large markets were rejecting the subordinate role in their interactions with the EMT and asserting their subject position as distinctive and powerful markets that should formulate their own local strategy.

However, the EMT were increasingly convinced that local markets were largely undifferentiated, and so should conform to a central, EMT-formulated strategy. They used the planning process as a standardization mechanism to control local differentiation and reinforce their own dominance in strategy communications:

Yesterday one country was saying we want to do educational promotions, and we are developing such a programme. And we say to them no you shouldn't do that, you should stop it, we have got it in our plans. We will deliver it to you, you don't need to invest money, put that money into something else. (EMT)

Thus, the EMT extended their own scope as strategy formulators and reduced the opportunities for local teams to participate in strategy formulation. Planning was extended from communicating a central strategy to providing many additional elements with which the local markets were to comply. In effect, the EMT now perceived that, in order to complement their own subject position as strategy formulators, the appropriate subject positions of local markets was to be strategy implementers:

[They] should not be planning strategy, they should not be developing campaigns; their remit is very different now. Therefore the way that they are going to go through the planning is more about how do I take what the EMT is putting out, and implement it brilliantly.

Large markets protested that this was outside the EMT remit. They were assuming too much control over local strategy:

I think they have exceeded the remit, because they have provided the strategy . . they have provided material, they have delivered a programme of market shaping, and also a process in order to improve market access across Europe, and in my understanding this was not in their ... I have been surprised that they have delivered the market building and the market access campaign. (France)

In response, the large markets disparaged the EMT market planning process as inferior to local planning processes:

They didn't do a competitor review, and they didn't do a segmentation review, and they hadn't sort of; they hadn't done all the stuff they were asking us to do and yet they'd got key issues and you kind of thought, why haven't they. (UK) 
They also criticized the dominant-subordinate dynamic of the EMT in integration activities:

The marketing campaign, when we adjusted it for the German market, and we had to ask for approval in the EMT, and we went through each page and so on, this is more in a direction of centralization. (Germany)

Tension mounted, as large markets resisted their EMT-allocated position as strategy implementers. The EMT reacted by asserting their position as strategy formulators for Europe, and exerting dominance in their interactions with the large markets:

We are not negotiating with them, we are politely trying to explain to them why they should do it. It's a process that we have been tasked to do, either that or every country will go back and do their own thing just with a different look, which is not the point, the point is to have a consistent campaign, both in terms of the way it looks and its content. (EMT)

While large markets insisted that the planning process was too standardized and needed modifying to local demands, the EMT prevented them from adapting the EMT-driven brand campaign. Instead of complying with the changes, the large markets resisted:

So if I am saying we are implementing the strategy, and we are using the sales aid, even if we are saying we are adapting it to the German market maybe slightly, this should be possible. (Germany)

In particular, a confrontation arose over the UK market's insistence that they needed a different campaign because that was best for their market revenues. The large markets were emphasizing their power as knowledgeable strategy formulators in local markets.

Drawing on their successful experiences in generating common strategy with the smaller markets, the EMT insisted that strategic planning was about standardization:

If your model is doing things $90 \%$ right across the whole of Europe is better than every market trying to do it $100 \%$ right in their market, then your bottom line has got to be that that applies equally to the bigger markets as to the smaller.

They particularly wanted the defiant UK to comply:

The challenge with the UK is for the UK to not to set a bad example if you want, about exemption from the rules, so that other markets can pick it up and use it as an example to be inconsistent within the European strategy or the European campaign. $(\mathrm{EMT})$

However, the UK refused to accept EMT jurisdiction, appealing to their country President, who was also the sponsor of the EMT, to adjudicate, on the basis that their 
local market expertise and their strong revenue, would be damaged by the common campaign:

What we want to make sure happens is that we have got the strongest messages that we possibly can, and that we don't lose out on that.

It was made clear to the EMT that as far as large local markets were concerned, the new planning process risked Brandco's profitability, with large markets asserting their rights to pursue local activities.

At the end of Phase 2, the planning process had thus had only partial success in generating a common European strategy. Managers in small markets accepted their allocated subject positions as strategy implementers, subordinated themselves to the standardized planning process and so began to experience the integration activities as positive and appropriately dominant-subordinate in terms of communication and participation. However, actors in large markets resisted the allocated position of strategy implementers and attempted to modify the planning process in order to assert themselves as strategy formulators and avoid a subordinate role in their interactions with the EMT.

\section{Phase 3}

From October onwards, following the resistance in Phase 2, there was much face-to-face discussion between the EMT, the UK president, the UK market, and the other large markets. Eventually, assured by the UK President as the EMT sponsor, that he would authorize the changes that markets such as the UK wanted to make, the EMT made compromises, such as allowing the UK to modify their campaign:

So there was a conscious compromise in several areas in order to get the model working and delivering. (EMT)

More importantly, in order to account for knowledge and expertise in local markets, the planning process was modified to include red, amber, and green categories. These modifications indicated where European strategy and messages must be asserted (red), where local activities could take precedence (green), and amber areas that were to be negotiated around a mix of local and European activity, which would involve greater interaction between these large markets and the EMT. At the same time, the EMT was still authorized to develop a common European strategy. The EMT's right to standardize much future planning was emphasized; strategic activity was to be seen as 90-95\% undifferentiated.

EMT are strategy formulators who seek active participation from large markets in formulating local campaigns. The EMT was pleased to have their position as strategy formulators reinforced hierarchically:

If it's a much better thing for 95\% of the markets then we should do it. People should think European and what's best for Europe. 
At the same time, they had made a subtle but important modification to their understanding of common European strategy. They now recognized that in their efforts to achieve a common strategy they needed to acknowledge and allow for large market differences, where subtle differentiations were specifically geared to maximizing market share in those markets:

The variety tends to be in the more important markets. (EMT)

As they modified their understanding of common strategy to allow for small variations, so the EMT also modified the planning process, not only in those areas on which local markets could negotiate, but also in terms of opportunities for participation for the larger markets. They proposed to increase participation as part of their own acceptance that they needed to change from a dominant-subordinate dynamic in their interactions with large markets to one that enhanced co-determination of the common strategy:

Anna might take the lead on that, and pull a small team together from the UK, Germany and France ... They will do some work for a month, or 2 months, and then come back to report back ... if we just had us here, the group of 4 managers and myself, we were developing everything, we wouldn't have this European flavour.

Common strategy had to be sure to incorporate greater receptiveness to strategymaking in important markets, where some differentiation might be linked to profitability. Thus the EMT subtly modified their subject position, remaining strategy formulators but with more participation in formulation from the large markets.

Small markets embed their position as strategy implementers. Managers in the small markets were satisfied with the outcomes of the strategic planning process. Their own experience of the standardizing aspects of the planning process, with its associated subject position as strategy implementers, had been positive in raising their status in Brandco:

Being in a smaller market, even being the same seniority you know, puts you more in the higher up of the hierarchy in a way, so from my perspective I never had - I know what the purpose of this [the common strategy] was. (Nth EU)

These managers had also benefited from participation in the planning process, giving them a positive experience of their new subject position:

Quite happy implementing and the overall process I am quite happy with as well, because I think that you were kind of saving a lot of resources, because for me locally, working with my local agencies that were not fully into every data. So it was kind of, you know, kind of a massive effort in developing my local campaign. (SP)

These markets thus endorsed the common strategy and, in association, the standardized planning process: 
For me the most important thing is that you have a very well, a very robust plan, strategic plan, on a European basis which you kind of . . know is as good as it can be, and I think that is the major role and then to make sure that you have a European strategy that you stick to, and have a European position, and European campaigns, etc. (Nth EU)

Based on their own experience of participating in strategy implementation, these markets endorsed the subject position of the EMT as strategy formulators, suggesting that more EMT control over local strategy would be appropriate:

We cannot make it individually in 40 markets in isolation. We need a European approach, European vision. And the EMT represents that . . care should be taken that the EMT is not neutral or is not just coordination of local activities but has a very strong say. (Central EU)

These small markets thus became embedded in their allocated position as strategy implementers and embraced their own subordinate position and the dominance of the EMT.

Large markets assume a new subject position as strategy 'translators', aided by modifications to the planning process to enable greater participation. The large markets were aware that the planning process had changed their subject position. They were no longer strategy formulators but strategy translators:

It's changed absolutely everything. Because we don't develop them anymore [the campaigns], we don't work with ourselves for development, you know our big challenge now is brand translation. (UK)

While the modifications to the planning process to include amber and green areas, on which they could negotiate, were important face-saving devices that enabled them to better manage their perceptions of subordination in interactions with the EMT, they also recognized that their subject position had changed to translating a strategy formulated elsewhere:

So instead of developing our own campaign, we now have to translate a campaign. My brand managers were very creative in doing this, so its just that they are having a different completely new area to work on ... So it is certainly different if you are developing a campaign or just adapting one. (Germany)

Nonetheless, large markets were pleased that they had been able to modify some standardization within the planning process to accommodate their own position and interests:

I don't think the purpose was to standardize campaigns, that was a kind of by product I think. So they weren't going out to ... right, we have the same amount across 
Europe we will increase our sales by x number, I don't think that was the objective, I think the objective was let's improve the quality of the campaigns across Europe on average and that will give us say, a percentage sales increase. (UK)

Additionally, enhanced opportunities to participate in formulating strategy with the EMT, which had a more co-determining than dominant-subordinate dynamic, helped large markets to feel included in the planning process, whereas they had previously felt excluded, even when they were present in strategy communications from the EMT:

It's not planning; it's how you plan: face-to-face meetings always have a big advantage in terms of how you can interact, about how you can discuss these things, that is certainly the best way to bring things quickly forward. (Germany)

In effect, by modifying the planning process to accord some differential treatment to large markets, both to negotiate some areas of their strategy, and also to participate more in formulating the common strategy, the large markets had become resigned to their new subject position. They felt that they had been able to shape the process, which made its implications more acceptable. As they were given jurisdiction over some areas of their campaigns, they compared the increased participation favourably with their initial experiences of the planning process:

We have been involved more and more. Early on when we worked with the EMT it was very top down, but we have been more and more involved... so I am more comfortable when the local markets are supposed to implement this material as I am being involved in all the reflection and all the discussion. (FR)

Which is so much . . . because you own it. So we are all agreeing. We did it with a slide set. What was red, what was amber, and what was green. And we agreed it as a team, what you had to do. What you could debate, what you could change. . . But we didn't have that in June and that was the biggest difficulty why the campaign was harder to roll out. Why we kept going back and challenging things. (UK)

Increased codetermination of the strategy, combined with subtle modifications to the planning process, enabled greater acceptance of common strategy:

The key thing is that you find a consolidated view on something and then you put all the effort behind it from the European perspective and from the local perspective to bring things forward. So it is fair to say that you argue about things during the process, but if the decision is made, then everybody has to pull in the same direction. (Germany)

Indeed, while the planning process had significantly altered the subject position of large markets, the ability to negotiate along the way had also modified their view of that position, the common strategy and the planning process: 
We have had a few negotiations along the way, but now we have got it we are happy with it. . . To me for it to be a success is all teams working together all the time; I guess that communication should be ongoing. (UK)

By the end of Phase 3, subtle differences in the planning process had emerged that enabled two different interdependent subject positions. The EMT had one set of interdependent positions with the small markets, as they were strategy formulators to those markets' positions as strategy implementers. Modifications to enable these interdependent positions involved increased standardization in the planning mechanism and dominant-subordinate planning interactions. At the same time, the EMT had different interdependent positions as strategy formulators, in participation with large markets, who were strategy translators of the commonly agreed strategy. Modifications to the planning process in these relationships involved greater differentiation in plans and increased opportunities for participation that featured codetermination in planning interactions. These subtle differences reflected the different experience and power bases, and hence, interdependencies between different actors. Small markets were inexperienced in strategy formulation and dependent upon the EMT for resources to improve their planning, campaigns and Brand X profitability, while the EMT was dependent upon the large markets, with strong local planning experience, to continue delivering high levels of profitability within their local markets, even as they engaged with a common strategy.

\section{DISGUSSION}

This paper set out to explore the reciprocal relationship between the planning process, actors' subject positions, and the emergence of common strategic activity, in order to explain the process by which planning delivers strategic integration. Our findings show that specific modifications occurred in actors' subject positions, participation dynamics within the planning process, and changes to the planning mechanism over three phases. In particular, over the duration of the planning process, two different interdependent subject positions with the EMT emerged. These findings are used to develop a process model (Figure 1), that shows how different processes of strategic planning evolve to accommodate the interests of different groups of actors in delivering an integrated strategy. This conceptual model constitutes the core contribution of our study. We now discuss each element of this model.

Figure 1 shows the variation in two contextual characteristics of business units, planning experience and intra-organizational power (A), that were consequential for the way that the planning process evolved in our study. Actors in the large European markets had significant experience in strategic planning, which they perceived as equal or even superior to the experience of the EMT, particularly in terms of local strategy. By contrast, actors in small markets had little planning experience. At the same time, the large European markets had high power within Brandco, particularly over Brand X, because they were important sources of revenue, whereas small markets had less power due to less revenue-generating potential in Brand $\mathrm{X}$. These contextual characteristics 


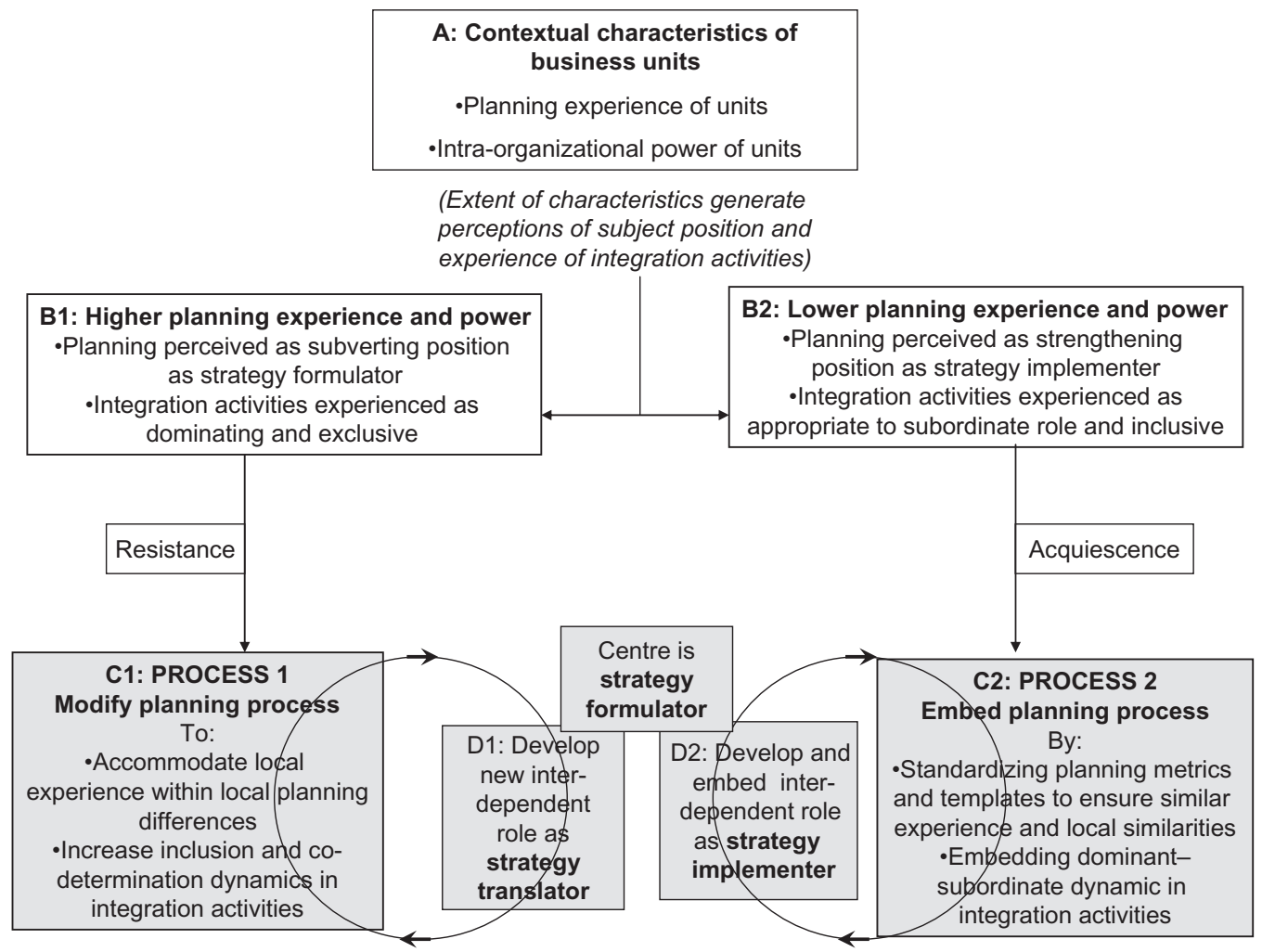

Figure 1. Process model of developing integration in strategic planning processes

had implications for the way that these different markets perceived their allocated position as strategy implementers at the outset of the planning process, and also for their experiences of integration activities.

For the large markets, with higher planning experience and intra-organizational power (B1), the planning process was perceived as subverting their existing position as strategy formulators. At the same time, they experienced integration activities involving participation in and communication of the common strategy, as not inclusive. As shown in Phases 1 and 2 of the findings, even when they were present in specific integration events, such as the initial campaign presentation in June, they experienced these as top-down communications that excluded them from active participation in formulating strategy. They thus felt that the EMT dominated integration events, relegating others to a subordinate role, which further reinforced their perception that their planning experience was not valued and that they were losing their position as strategy formulators. By contrast, small markets with little planning experience or intra-organizational power (B2), perceived that the planning process strengthened their position as strategy implementers by providing them with resources and access to the centre that they would otherwise not have. They therefore experienced integration activities as positive. Even when they realized that they were not participating in strategy formulation, but rather being communicated to about strategy implementation, they accepted that this subor- 
dinate role was appropriate to their experience and power and thus felt that the integration activities were inclusive. These different experiences had implications for the way that the planning process evolved for the two groups.

As explained in Phase 2 of the findings, the negative experiences of the large markets meant that they resisted their EMT-allocated position as strategy implementers, leading to Process $1(\mathrm{C} 1)$ in our model. Process 1 captures the findings from Phase 3, by explaining how the planning mechanism was modified in order to accommodate local planning experience and planning differences in local markets. Modifications also involved changes in participation activities, in order to increase inclusion and modify the dynamic from one of a dominant EMT communicating strategy to a subordinate local market. Rather, greater participation in formulating strategy for the European market as a whole and for large local markets in particular, introduced a codetermination dynamic that enabled actors in those markets to feel included in formulating strategy. Despite increased inclusion, it is important to recognize that the political struggles that took place over these modifications to the planning process also involved modifications to the subject position of large markets. Increased participation and greater discretion over local market planning increased their perceptions of inclusion and codetermination but also enabled them to become resigned to their own changing position. Thus, they began to refer to themselves as strategy translators (D1), which was a less subordinate position than simply being an implementer of a strategy formulated elsewhere. By assuming a position as strategy translators, large markets were able to develop interdependent subject positions with the EMT as strategy formulators.

By contrast, as illustrated in Phase 2 of the findings, small markets' acceptance of a subordinate role and their experiences of the planning process as inclusive meant that they acquiesced with their EMT-allocated position as strategy implementers, leading to Process 2 (C2) in our model. Process 2 shows how the strategic planning process was embedded within these markets through greater standardization of the planning metrics and templates, in order to ensure that a similar strategy was followed in all markets. Importantly, as shown in Phase 3 of the findings, in normalizing the standardized planning process, the small markets further embedded their own position as strategy implementers (D2) and endorsed the dominant-subordinate dynamics of the integration activities. Indeed, they called for greater EMT control to ensure similar strategic planning and common activity across all markets. Thus, the small markets actively assumed an interdependent position of strategy implementers with the EMT as strategy formulators.

This explanation of our process model (Figure 1) illustrates how, in shaping the planning process the subject positions of the key actors were also shaped, until a position of common strategy could be reached. This process model thus answers our research question by showing the specific processes through which a planning process aimed at strategic integration and the actors engaged in that process shape each other, until a situation emerges in which different actors are able to pursue largely common strategy. Furthermore, the model explains variations in this process according to different business unit characteristics and, hence, different experiences of integration activities, leading to different processes and subject positions, even within a single case organization. 


\section{IMPLICATIONS AND GONGLUSIONS}

Figure 1 presents an empirically-grounded process model of our findings. This model contributes to the literature on the integrative effects of strategic planning, politics and participation in the strategy-making process, activity theory and the strategy-as-practice perspective. First, our study makes a contribution to the literature on the integrative effects of strategic planning. Strategic planning has been found to have integrative effects, uniting diverse units under common strategic goals through the activities of participation and communication (Andersen, 2004; Ketokivi and Castañer, 2004; Lines, 2004). However, as discussed in the theoretical framework, while we know that strategic planning has integrative effects, less is known about how such integration occurs, particularly given the different interests and roles that different actors bring to the strategy process (Balogun and Johnson, 2004; Burgelman, 1983; Floyd and Lane, 2000; Mantere and Vaara, 2008). At least part of this problem is that much of the research in this area has been cross-sectional and survey-based, so that it is unclear how communication and participation enables integration, leading Wooldridge et al. (2008) to call for fine-grained studies of strategic planning dynamics that extend existing studies by explaining those conditions under which sub-unit interests would be aligned with those of the wider organization.

Our process model has addressed this concern by showing those business unit characteristics of planning experience and relative power under which sub-units experience and respond differently to the integrative effects of strategic planning. Furthermore, by drawing on the literature on politics and power in strategy-making, we have been able to elaborate existing findings on participation and communication in the planning process. Using Westley's (1990) concepts of inclusion and exclusion, and dominant, subordinate, or co-determinant interactions within strategic conversations, we show the specific ways that business unit characteristics of planning experience and intra-organizational power affect different units' experiences of participation and communication. Actors in more powerful and experienced units experience the same participation and communication activities as dominant and exclusive, while actors in less powerful and experienced units experience those activities as inclusive and accept their subordinate role. Hence, integration activities need to vary, in order to provide higher levels of participation and enable codetermination of strategic goals for those units with higher planning experience and power. Strategic planning thus must be varied in the way that it is rolled out across different business units, in order to have integrative effects on the organization as a whole.

In making this contribution to the planning literature, we also extend Westley's (1990) concepts, which were grounded in vignettes of individual conversations with middle managers but had not been extended to a longitudinal study. Our study explains how interaction dynamics change over a series of strategic conversations, such as those which occur in a planning process. First, we show, empirically, that even where managers are physically present or included in a strategic conversation, they may feel excluded if the interaction dynamic is dominated by one party, in our case the EMT, allocating a subordinate role to others in the process. Thus, exclusion from strategy conversation can occur, even when physical inclusion occurs. Second, we 
show that the extent to which a subordinate role in a strategic conversation lessens commitment to strategic goals is dependent upon the extent to which the subordinated actors accept the role allocated to them, as with our small markets. Thus, subordination may be a positive or negative experience according to the starting position of two parties in a strategic conversation. Third, our findings show how conversational roles and dynamics can evolve over the course of a planning process, as both parties, through a range of political interactions, learn how to develop interaction dynamics that are appropriate to their relative status. For example, conversations with large markets evolved into codetermination of strategy, whereas those with smaller markets remained dominant and subordinate. We thus suggest that there is a processual relationship in Westley's (1990) concepts that might benefit from further research over a larger sample of cases.

Our findings also extend existing research into politics and different roles and subject positions within the strategy process. Our study elaborates Narayanan and Fahey's (1982) concepts, by showing how actors are allocated or assume different positions within the strategy process and the political implications of allocating particular positions. We show that, where actors are allocated subordinate positions within the strategy process, particularly where these involve change of position, such as moving from strategy formulators to strategy implementers, resistance is likely to occur. The extent of resistance or acquiescence to an allocated strategy position depends upon those actors' existing power bases. Furthermore, actors will need time to interact with others in order to move from a perception of imposition about allocated roles to one in which they have negotiated the role that they are willing to assume, as found with our large markets. Thus, concepts of incrementalism (Johnson, 1988; Quinn, 1980) remain pertinent, not only for allowing senior managers to learn from and respond to political and emotional reactions to change, but also for allowing lower level managers to renegotiate their positions within the planning process.

While strategy process, context, and outcomes are understood to co-evolve in a dynamic and ongoing process (Chakravarthy and White, 2002), there are few studies that adopt an explicit ontological approach to the evolving interaction between these elements of strategy making (Jarzabkowski, 2008; Johnson et al., 2007; Orlikowski, 1996, 2000; Whittington, 2006). The activity theory basis of our study allowed us to explain how strategic integration emerges as an outcome of the strategic planning process through the evolving and reciprocal relationship between the subject positions of different actors and their modifications to the planning process. We thus provide valuable insights into the reciprocal processes by which actors, strategic plans and strategic outcomes shape and are shaped by each other. Our framework might thus provide a valuable theoretical underpinning for other strategy practice and process researchers.

This study also contributes to organizational research that takes an activity theory perspective. Our findings provide empirical evidence of the 'retooling' process (Miettinen and Virkkunen, 2005), through which a planning mechanism, put in place to achieve strategic integration, was modified both in its specific mechanisms, such as the extent of standardized templates and campaigns, and also in the participation activities that took place within that process. These modifications not only accommodated different actors' interests but also reshaped their subject positions, so that they could develop varying but 
sufficiently interdependent positions that the organization could function as an activity system pursuing a largely common strategy. This paper furthers activity theory by illustrating the power dynamics involved in retooling, which have been insufficiently examined in activity theory (Blackler and McDonald, 2000), leading to some criticisms that it offers an over-socialized view of common activity (e.g. Handley et al., 2006, p. 642). Our findings show that not only is power implicated in how the planning mechanism is modified, as those more powerful actors had the capacity to engage in modifications, but also that changing power positions are mediated through those modifications (Adler, 2005); large markets became reconciled to their new subject position as they modified the process to account for their power difference. Power is thus a product and a medium of the mediation process as actors interact with their world, which might fruitfully be further explored in activity theory.

Finally, this paper contributes to a practice perspective on strategy as a situated, socially accomplished activity, constructed through the actions, interactions, and negotiations of multiple actors (Balogun et al., 2007; Jarzabkowski, 2004; Jarzabkowski et al., 2007; Johnson et al., 2003, 2007; Mantere, 2008; Whittington, 2006). The strategy-aspractice research agenda has a particular concern to explain how the social practices and activities of multiple actors are consequential for organizational strategy. Our practicebased activity framework (Jarzabkowski, 2009), shows how common strategic activity is constructed over time between different sub-units, as they negotiate their subject positions and the way that the planning process will be enacted in their local contexts. Our study thus contributes to the strategy-as-practice agenda by drawing upon a framework that can capture the interaction and negotiation between different communities over a planning process. We show how this interaction and negotiation, by modifying the planning process to better accommodate different interests, enabled the social and political accomplishment of a common strategy within Brandco. From a practice perspective, we may better understand how strategic planning enables participation, communication, and integration but also how an organization may neglect the socio-political dynamics through which planning and its associated activities are accomplished.

Our findings thus have implications for practice. The central contribution of this study is captured in the process model in Figure 1 and centres around the point that for strategic planning to deliver integration, it needs to be conceived of as a process of co-evolution, in which diverse participants with different levels of planning expertise and power seek to modify the process to better accommodate the subject positions they wish to retain rather than the positions they are being assigned in related participation and communication activities. Through time this leads to shifts in the subject positions as well the planning process. As such strategic integration is something that has to be co-created through negotiation rather than something than can be imposed. Managers need to be aware that people, with their divergent interests, goals, and power bases, do strategic planning. To deliver integration a strategic planning process needs to take account of the divergent interests that people bring to that process. A common framework is more likely to be developed when socio-political interests, such as different levels of experience and gains or losses in power are considered in advance of implementing a new process. Additionally, it is important to recognize and incorporate into the planning process the valuable local knowledge that resides within different parts of the organization. While 
these seem to be obvious prescriptions to increase participation within the strategymaking process, our case shows that they may be easily forgotten in practice. Therefore, when implementing strategic planning as an integrative device, managers might develop a more differentiated, rather than standardized process, that accommodates different levels of participation according to the divergent interests, experience, and power bases of key players.

\section{AGKNOWLEDGMENTS}

The authors gratefully acknowledge financial support in the preparation of this manuscript from the UK ESRC/EPSRC/Advanced Institute of Management (AIM) Research: RES-331-25-3014 (Balogun) and RES-331-25-3013 (Jarzabkowski). We would also like to thank the editors and the three anonymous reviewers for their help with the development of this manuscript.

\section{REFERENCES}

Ackoff, R. L. (1970). Concept of Strategic Planning. London: Wiley-Interscience.

Adler, P. (2005). 'The evolving object of software development'. Organization, 12, 401-35.

Andersen, T. J. (2000). 'Strategic planning, autonomous actions and corporate performance'. Long Range Planning, 33, 184-200.

Andersen, T. J. (2004). 'Integrating decentralized strategy making and strategic planning processes in dynamic environments'. Fournal of Management Studies, 41, 1271-99.

Balogun, J. and Johnson, G. (2004). 'Organizational restructuring and middle manager sensemaking'. Academy of Management Fournal, 47, 523-49.

Balogun, J. and Johnson, G. (2005). 'From intended strategy to unintended outcomes: the impact of change recipient sensemaking'. Organization Studies, 26, 1573-602.

Balogun, J., Huff, A. and Johnson, P. (2003). 'Three responses to methodological challenges of studying strategizing'. Fournal of Management Studies, 40, 197-224.

Balogun, J., Hope Hailey, V., Gleadle, P. and Willmottt, H. (2005). 'Managing change across boundaries: boundary shaking practices'. British fournal of Management, 16, 261-78.

Balogun, J., Jarzabkowski, P. and Seidl, D. (2007). 'Strategizing activity and practice'. In Ambrosini, V. and Jenkins, M. (Eds), Advanced Strategic Management. Basingstoke: Palgrave Macmillan, 196-211.

Bartkus, B., Glassman, M. and McAfee, R. B. (2000). 'Mission statements: are they smoke and mirrors?'. Business Horizons, 43, 23-8.

Beer, M. and Eisenstat, R. A. (2000). 'The silent killers of strategy implementation and learning'. Sloan Management Review, 41, 29-40.

Blackler, F. (1993). 'Knowledge and the theory of organizations: organizations as activity systems and the reframing of management'. Fournal of Management Studies, 30, 863-84.

Blackler, F. (1995). 'Knowledge, knowledge work and organizations: an overview and interpretation'. Organization Studies, 16, 1021-46.

Blackler, F. and McDonald, S. (2000). 'Power, mastery and organizational learning'. Fournal of Management Studies, 37, 833-52.

Blackler, F., Crump, N. and McDonald, S. (2000). 'Organizing processes in complex activity networks'. Organization, 7, 277-300.

Bower, J. L. (1970). Managing the Resource Allocation Process. Boston, MA: Harvard University Press.

Brews, P. J. and Hunt, M. (1999). 'Learning to plan and planning to learn: resolving the planning school/ learning school debate'. Strategic Management Fournal, 20, 889-914.

Burgelman, R. A. (1983). 'A process model of internal corporate venturing in the diversified major firm'. Administrative Science Quarterly, 28, 223-44.

Burgelman, R. A. and Grove, A. S. (1996). 'Strategic dissonance'. California Management Review, 38, 8-28.

Chakravarthy, B. and Doz, Y. (1992). 'Strategy process research: focusing on corporate self-renewal'. Strategic Management Fournal, 13, Special Issue, 5-14.

Chakravarthy, B. S. and Lorange, P. (1991). Managing the Strategy Process: A Framework for a Multibusiness Firm. Englewood Cliffs, NJ: Prentice Hall. 
Chakravarthy, B. S. and White, R. E. (2002). 'Strategy process: making, shaping and validating strategic decisions'. In Pettigrew, A., Thomas, H. and Whittington, R. (Eds), Handbook of Strategy and Management. Beverly Hills, CA: Sage, 182-205.

Driscoll, J. (1978). 'Trust and participation in organisational decision making as predictions of. satisfaction'. Academy of Management Fournal, 21, 44-56.

Dutton, J. E. and Duncan, R. B. (1987). 'The creation of momentum for change through the process of strategic issue diagnosis'. Strategic Management fournal, 8, 279-95.

Eisenhardt, K. (1989). 'Building theories from case study research'. Academy of Management Reviewe, 14, 53250.

Eisenhardt, K. M. and Bourgeois, L. J. (1988). 'Politics of strategic decision making in high velocity environments: toward a midrange theory'. Academy of Management Fournal, 31, 737-70.

Engestrom, Y. (1993). 'Developmental studies of work as a testbench of activity theory: the case of primary care medical practice'. In Chaiklin, S. and Lave, J. (Eds), Understanding Practice: Perspectives on Activity and Context. Cambridge, MA: Cambridge University Press, 64-103.

Engestrom, Y., Miettinin, R. and Punamaki, R-L. (Eds) (1999). Perspectives on Activity Theory. Cambridge, MA: Cambridge University Press.

Evered, R. and Louis, M. (1981). 'Alternative perspectives in the organizational sciences: "inquiry from the inside" and "inquiry from the outside" '. Academy of Management Review, 6, 385-96.

Floyd, S. W. and Lane, P. M. (2000). 'Strategizing throughout the organization: managing role conflict in strategic renewal'. Academy of Management Reviere, 25, 154-77.

Floyd, S. W. and Wooldridge, B. (1997). 'Middle management's strategic influence and organizational performance'. Fournal of Management Studies, 34, 465-85.

Foot, K. A. (2000). 'Pursuing an evolving object: a case study in object formation and identification'. Mind, Culture and Activity, 9, 56-83.

Ghoshal, S. and Bartlett, C. A. (1998). Managing Across Borders, 2nd edition. London: Random House.

Grant, R. (2003). 'Strategic planning in a turbulent environment: evidence from the oil majors'. Strategic Management fournal, 24, 491-517.

Guth, W. D. and Macmillan, I. C. (1986). 'Strategy implementation versus middle manager self-interest'. Strategic Management Fournal, 7, 313-27.

Handley, K., Sturdy, A., Clark, T. and Fincham, R. (2006). 'Within and beyond communities of practice-making sense of learning through participation, identity and practice'. Fournal of Management Studies, 43, 641-55.

Hardy, C., Palmer, I. and Phillips, N. (2000). 'Discourse as a strategic resource'. Human Relations, 53, $1227-48$.

Jarzabkowski, P. (2003). 'Strategic practices: an activity theory perspective on continuity and change'. Fournal of Management Studies, 40, 23-55.

Jarzabkowski, P. (2004). 'Strategy as practice: recursiveness, adaptation and practices-in-use'. Organization Studies, 25, 529-60.

Jarzabkowski, P. (2005). Strategy as Practice: An Activity-Based View. London: Sage.

Jarzabkowski, P. (2008). 'Shaping strategy as a structuration process'. Academy of Management Fournal, 51, 621-50.

Jarzabkowski, P. (2009). 'An activity-theory approach to strategy-as-practice'. In Golsorkhi, D., Rouleau, L., Seidl, D. and Vaara, E. (Eds), Handbook of Strategy-as-Practice. Cambridge: Cambridge University Press, forthcoming.

Jarzabkowski, P., Balogun, J. and Seidl, D. (2007). 'Strategizing: the challenges of a practice perspective'. Human Relations, 60, 5-27.

Johnson, G. (1988). 'Re-thinking incrementalism'. Strategic Management Fournal, 9, 75-91.

Johnson, G., Melin, L. and Whittington, R. (2003). 'Micro strategy and strategizing: towards an activitybased view?'. Fournal of Management Studies, 40, 3-22.

Johnson, G., Langley, A., Melin, L. and Whittington, R. (2007). Strategy as Practice: Research Directions and Resources. Cambridge: Cambridge University Press.

Kaptelinin, V. and Nardi, B. (2006). Acting with Technology: Activity Theory and Interaction Design. Cambridge, MA: MIT Press.

Ketokivi, M. and Castañer, X. (2004). 'Strategic planning as an integrative device'. Administrative Science Quarterly, 49, 337-68.

Korsgaard, M. A., Schweiger, D. M. and Sapienza, H. J. (1995). 'Building commitment, attachment, and trust in strategic decisions'. Academy of Management Fournal, 38, 60-85.

Kotter, J. P. (1995). 'Leading change: transformation efforts fail'. Harvard Business Review, 73, 59-67. 
Kozulin, A. (1990). Vygotsky's Psychology: A Biography of Ideas. Cambridge, MA: Harvard University Press.

Langley, A. (1999). 'Strategies for theorizing from process data'. Academy of Management Review, 24, 691-710.

Leontiev, A. N. (1978). Activity, Consciousness, and Personality. Englewood Cliffs, NJ: Prentice-Hall.

Liedtka, J. (2000). 'Strategic planning as a contributor to strategic change: a generative model'. European Management Fournal, 18, 195-206.

Lincoln, Y. S. and Guba, E. G. (1985). Naturalistic Inquiry. London: Sage.

Lines, R. (2004). 'Influence of participation in strategic change: resistance, organizational commitment and change goal achievement'. Fournal of Change Management, 4, 193-215.

Lorange, P. (1975). 'Divisional planning: setting effective direction'. Sloan Management Review, 17, 77-91.

Mantere, S. (2008). 'Role expectations and middle manager strategic agency'. Fournal of Management Studies, 45, 294-316.

Mantere, S. and Vaara, E. (2008). 'On the problem of participation in strategy: a critical discursive perspective'. Organization Science, 19, 341-58.

Marginson, D. E. W. (2002). 'Management control systems and their effects on strategy formation at middle-management levels: evidence from a UK organization'. Strategic Management Fournal, 23, 1019 31.

Miettinen, R. and Virkkunen, J. (2005). 'Epistemic objects, artefacts and organizational change'. Organization, 12, 437-56.

Miles, M. and Hubermann, A. (1994). An Expanded Sourcebook Qualitative Data Analysis. London: Sage.

Miller, C. C. and Cardinal, L. B. (1994). 'Strategic planning and firm performance: a synthesis of more than two decades of research'. Academy of Management Fournal, 37, 1649-65.

Mintzberg, H. (1994). The Rise and Fall of Strategic Planning. New York: Free Press.

Musson, G. and Duberley, J. (2007). 'Change, change or be exchanged: the discourse of participation and the management of identity'. Foumal of Management Studies, 44, 143-64.

Narayanan, V. K. and Fahey, L. (1982). 'The micro-politics of strategy formation'. Academy of Management Review, 7, 25-34.

Omicini, A. and Ossowski, S. (2004). 'Coordination and collaboration activities in cooperative information systems'. International Fournal of Cooperative Information Systems, 13, $1-7$.

Orlikowski, W. (1996). 'Improvising organizational transformation over time: a situated change perspective'. Information Systems Research, 7, 63-9.

Orlikowski, W. (2000). 'Using technology and constituting structures: a practice lens for studying technology in organizations'. Organization Science, 11, 404-28.

Pettigrew, A. (1990). 'Longitudinal field research on change theory and practice'. Organization Science, 1, 267-92.

Quinn, J. B. (1980). Strategies for Change: Logical Incrementalism. New York: Irwin.

Rabardel, P. and Beguin, P. (2005). 'Instrument mediated activity: from subject development to anthropocentric design'. Theoretical Issues in Ergonomics Science, 6, 429-61.

Rigby, D. (2003). 'Management tools survey 2003: usage up as companies strive to make headway in tough times'. Strategy and Leadership, 31, 4-11.

Rouleau, L. (2005). 'Micro-practices of strategic sensemaking and sensegiving: how middle managers interpret and sell change every day'. Fournal of Management Studies, 42, 1413-43.

Sagie, A. and Koslowsky, M. (2000). Participation and Empowerment: Modelling, Effectiveness, and Applications. Thousand Oaks, CA: Sage.

Schaffer, U. and Willauer, B. (2003). 'Strategic planning as a learning process'. Schmalenbach Business Reviere, 55, 86-108.

Simon, H. (1964). 'On the concept of organizational goal'. Administrative Science Quarterly, 9, 1-22.

Spender, J.-C. (1995). 'Organizations are activity systems, not merely systems of thought'. Advances in Strategic Management, 11, 151-72.

Suddaby, R. (2006). 'What grounded theory is not'. Academy of Management Fournal, 49, 633-42.

Vancil, R. F. and Lorange, P. (1975). 'Strategic planning in diversified companies'. Harvard Business Review, 53, $81-90$.

Vygotsky, L. (1978). Mind in Society: The Development of Higher Psychological Processes. Cambridge, MA: Harvard University Press.

Westley, F. R. (1990). 'Middle managers and strategy: the micro-dynamics of inclusion'. Strategic Management Fournal, 11,337-52.

Whittington, R. (2006). 'Completing the practice turn in strategy research'. Organization Studies, 27, 613-34.

Whittington, R. and Cailluet, L. (2008). 'The crafts of strategy'. Long Range Planning, 41, 241-7.

Wilson, I. (1994). 'Strategic planning isn't dead - it changed'. Long Range Planning, 27, 12-24. 
Wooldridge, B. and Floyd, S. W. (1989). 'Strategic process effects on consensus'. Strategic Management Fournal, 10, 295-302.

Wooldridge, B. and Floyd, S. W. (1990). 'The strategy process, middle management involvement, and organizational performance'. Strategic Management Fournal, 11, 231-41.

Wooldridge, B., Schmidt, T. and Floyd, S. (2008). 'The middle management perspective on strategy process: contributions, synthesis, and future research'. Fournal of Management, 34, 1190-221. 